\title{
C2C12 myoblastoma cell differentiation and proliferation is stimulated by androgens and associated with a modulation of myostatin and Pax7 expression
}

\author{
P Diel, D Baadners, K Schlüpmann, M Velders and J P Schwarz \\ Department of Molecular and Cellular Sports Medicine, Institute of Cardiovascular Research and Sports Medicine, Center for Preventive Doping Research, German Sport University \\ Cologne, 50927 Cologne, Germany \\ (Correspondence should be addressed to P Diel; Email: diel@dshs-koeln.de)
}

\begin{abstract}
Androgens are modulators of skeletal muscle adaptation and regeneration processes. The control of satellite cell activity is a key mechanism during this process. In this study, we analyzed the ability of dihydrotestosterone (DHT) and anabolic steroids to induce and modulate the differentiation of $\mathrm{C} 2 \mathrm{C} 12$ myoblastoma cells toward myotubes. C2C12 cells were dose-dependently treated with DHT and anabolic steroids. The time-dependent effects on differentiation were measured and correlated with the expression of genes involved in the regulation of satellite cell activity. The distribution of $\mathrm{C} 2 \mathrm{C} 12$ cells within the cell cycle was measured by flow cytometry and differentiation by creatine kinase (CK) activity. Gene expression was analyzed using quantitative real-time PCR and confocal microscopy. The treatment with DHT and anabolic steroids resulted in a stimulation of $\mathrm{C} 2 \mathrm{C} 12$ cell proliferation and $\mathrm{CK}$ activity. The antiandrogen flutamide was able to antagonize this effect. The expression of the androgen receptor, SOX8, SOX9, Delta, Notch, myostatin, and paired box gene7 (Pax7) was modulated by androgens. The treatment with DHT and anabolic steroids resulted in a strong stimulation of myostatin expression not only in undifferentiated cells but also in myotubes. The stimulation could be antagonized by flutamide. The expression of Pax7 was detectable in $\mathrm{C} 2 \mathrm{C} 12$ cells early after treatment with DHT. Our results demonstrate that the key mechanisms of satellite cell differentiation are modulated by androgens. Androgens stimulate the proliferation of $\mathrm{C} 2 \mathrm{C} 12$ cells, accelerate the process of differentiation, and increase the expression of myostatin in undifferentiated and differentiated cells. Our findings may have implications not only for the treatment of muscular diseases but also for the improvement of doping analytical methods.
\end{abstract}

Journal of Molecular Endocrinology (2008) 40, 231-241

\section{Introduction}

Skeletal muscle possesses the ability to both respond and adapt to changing environmental stimuli, leading to a set of metabolic and morphological adaptations, which allow the tissue to better meet the energy demands of sustained physical activity. Endocrine factors influence muscle growth and development throughout life. It has been demonstrated that not only hormonal excess but also deficiency adversely affect both muscle structure and function (Veldhuis et al. 2005). An example is the extreme potency of androgens and anabolic steroids to increase skeletal muscle mass. However, the molecular mechanisms involved in this anabolic activity are still only poorly understood. Muscle cells function as a syncitium, with several nucleated cells fusing to form the muscle fiber the key cellular activator of this process is the satellite cell (Wozniak et al. 2005). Satellite cells are located beneath the basal lamina of muscle fibers and are a distinct muscle cell subtype responsible for postnatal adaptation, growth, and repair (Mauro 1961, Chen et al. 2005). Satellite cells have a variety of potential fates, including proliferation, fusion, and trans-differentiation (Zammit et al. 2004). Satellite cell biology is affected by a variety of factors; of special interest are the influence of mechanical stimulation, ageing, and endocrine factors (Scimè \& Rudnicki 2004, Dhawan \& Rando 2005, Wozniak \& Anderson 2005). Besides growth hormone and insulin-like growth factor-I, androgens and myostatin are described to effect satellite cell proliferation and differentiation. Immunohistochemical examinations show that androgen receptors (ARs) are expressed in CD34+ cells, fibroblasts, smooth muscle cells, and satellite cells (Sinha-Hikim et al. 2004). Several papers describe the effects of androgens on the modulation of myoblast fusion (Artaza et al. 2005), C2C12 cell differentiation and proliferation (Benjamin et al. 2004), and a modulation of gene expression in satellite cells (Lee 2002) exposed to androgens. Beside androgens, the growth factor myostatin affects the differentiation and 
proliferation of satellite cells. Myostatin was first discovered by McPherron et al. (1997) who demonstrated that a phenotype of exaggerated muscle hypertrophy correlated with mutations in the myostatin gene. Such naturally occurring knockout mutations of myostatin have also been described in animals (Grobet et al. 1997) and in a human child (Schuelke et al. 2004). Myostatin knockout mice show an increased satellite cell proliferation compared with wild-type controls (Wagner et al. 2005). There is increasing evidence that myostatin is an important factor maintaining satellite cells in a state of reversible quiescence (Amthor et al. 2006). Myostatin signaling involves the interaction with MRFs, inhibiting the synthesis and activity of MyoD (Amthor et al. 2004, Guttridge 2004). At the cellular level, myostatin affects cell cycling by controlling the entry of satellite cells into the S-phase (McCroskery et al. 2003, Amthor et al. 2004).

Our recent observation that androgens and anabolic steroids modulate myostatin expression in rat skeletal muscle (Diel et al. 2007) provides evidence that both act synergistically to control skeletal muscle homeostasis. To prove this hypothesis and to elucidate the molecular mechanisms involved in the control of satellite cell activity by androgens and myostatin, we have analyzed the effects of androgens and anabolic steroids on C2C12 cell proliferation and differentiation. These effects were correlated with the expression of genes involved in the control of satellite cell activity and myostatin.

\section{Materials and methods}

\section{Materials and substances}

Tetrahydrogestrinone (THG) was provided by Schering AG (Berlin, Germany). Dihydrotestosterone (DHT) and flutamide were obtained from Sigma-Aldrich. Serum and culture media were purchased from Life Technologies. The following antibodies were used: myostatin MF408 (R\&D Systems, Wiesbaden, Germany), anti-goat T-7028TRITC conjugate (SigmaAldrich), paired box gene 7 (Pax7) antibody MAB 1675 (R\&D Systems), and biotinylated goat anti-rabbit immunoglobulins E 0432/Dako, Hamburg, Germany). VECTASHIELD HardSet Mounting Medium with $4^{\prime}$, 6-diamino-2-phenylindole (DAPI) VEC-H-1500 was provided by Biozol, Heidelberg, Germany).

\section{Creatine kinase (CK) activity}

CK activity was determined in cell lysates using the NADPH-coupled assay following the protocol supplied by the manufacturer (ABX Pentra CK NAC CP Nr.
A11A01632) and the diagnostic device ABX Pentra (Horiba ABX, Montpellier, France). The results are expressed as Units ( $\mu$ moles per minute) of NADPH formed per $\mu \mathrm{g} /$ total protein content of the homogenate of DNA, and are means \pm s.E.M. from duplicates of three independent experiments.

\section{Cell culture}

Mouse C2C12 myoblasts (American Type Culture Collection, Blau et al. 1985) were maintained in DMEM supplemented with $10 \%$ fetal serum (FS) and antibiotics, at $37^{\circ} \mathrm{C}$ and $5 \% \mathrm{CO}_{2}$. The differentiation medium contained 3\% horse serum instead of $10 \%$ FS10. The cells were passaged by trypsination $(0.5 \%$ trypsin in $0.5 \mathrm{mM}$ EDTA, Gibco BRL) from the culture plate at $70 \%$ confluence. To investigate the timedependent effects of androgens on proliferation and differentiation, 1000 cells per well were seeded in 24-well plates (Corning, Falcon) in the presence or absence of steroids. Steroids and antihormones were added from a $10^{3}$-fold concentrated stock solution in ethanol. The final ethanol concentration in the medium did not exceed $0 \cdot 1 \%$.

\section{Cell cycle analysis}

C2C12 cells were centrifuged $(500 \mathrm{~g})$ and gently resuspended in $1 \mathrm{ml}$ hypotonic fluorochrome solution (PI $50 \mu \mathrm{g} / \mathrm{ml}$ in $0 \cdot 1 \%$ sodium citrate plus $0 \cdot 1 \%$ Triton $\mathrm{X}-100$, Sigma) in polypropylene tubes. The tubes were placed at $4{ }^{\circ} \mathrm{C}$ in darkness for $4 \mathrm{~h}$ before flow cytometric analysis. The cell cycle analysis was performed as described by Diel et al. (2002).

\section{Fluorescence microscopy}

C2C12 cells were seeded at a rate of $1 \times 10^{3}$ cells $/ \mathrm{ml}$ in 24-well plates (Corning, Falcon) on cover slips. The cells were then fixed for 15 min with $2 \%$ paraformaldehyde/PBS, washed three times with PBS, and permeabilized for $15 \mathrm{~min}$ with $0.5 \%$ Igepal/PBS. They were blocked overnight in $1 \% \mathrm{BSA} / \mathrm{PBS}$ and incubated with the respective primary antibody (myostatin 1:50, Pax7 1:300) for $4 \mathrm{~h}$. The cells were washed three times in PBS and incubated with the conjugated secondary antibodies in $1 \% \mathrm{PBS} / \mathrm{BSA}$ at $4{ }^{\circ} \mathrm{C}$ for $1 \mathrm{~h}$ after which the cells were washed twice in PBS and once in Aqua bidest and embedded in Evanol or VECTASHIELD HardSet Mounting Medium with DAPI (DAPI staining). Fluorescence was observed using a Zeiss LSM 510 confocal microscope (Carl Zeiss, Oberkochen, Germany) with appropriate filters. 


\section{RNA preparation, reverse transcription, and real-time PCR}

Total cytoplasmic RNA was extracted from the liver and the gastrocnemius muscle using the standard TRIzol method (Life Technologies). DNA residues were eliminated by enzymatic digestion (DNase I, Ambion, Austin, USA). The absence of residual DNA was verified in a test PCR, which was controlled by PCR. SuperscriptTM II Reverse Transcriptase (Life Technologies) and Oligo(dT)12-18 were used for the first-strand cDNA synthesis.

Real-time PCR was performed with Platinum Taq DNA polymerase (Life Technologies) using the iCycler Thermal Cycler with iQ real-time Detection System (Bio-Rad). All reactions were run in triplicate. After vortexing, $50 \mu \mathrm{l}$ aliquots of the mixture were pipetted into each well of a 96-well thin-wall PCR plate (Bio-Rad). PCRs consisted of a denaturing cycle at $95^{\circ} \mathrm{C}$ for $3 \mathrm{~min}$, followed by 50 cycles of $1 \mathrm{~min}$ at $95^{\circ} \mathrm{C}, 1 \mathrm{~min}$ at $58^{\circ} \mathrm{C}$, and $1 \mathrm{~min}$ at $72^{\circ} \mathrm{C}$.
Fluorescence was quantified during the $58^{\circ} \mathrm{C}$ annealing step and product formation was confirmed by melting curve analysis $\left(55-94^{\circ} \mathrm{C}\right)$. Relative mRNA amounts of target genes were calculated after normalization to an endogenous reference gene (cyclophilin) and relative to the negative control (vehicle-treated control animals) with the arithmetic formula $2^{-\Delta \Delta C_{t}}$.

Based on the cDNA sequences available at the EMBL database, the following specific primer pairs were designed by the software Primer3 (Whitehead Institute for Biomedical Research, Cambridge, MA, USA; http:/ /www-genome.wi.mit.edu/cgi-bin/primer/primer3_www.cgi/) and confirmed by the sequences in the NCBI database (http://www.ncbi.nlm.nih.gov/). All the following primers were synthesized by MWG-Biotech AG (Ebersberg, Germany): myostatin sense primer, $5^{\prime}$-TAACCTTCCCAGGACCAGGA-3' ${ }^{\prime}$ and myostatin antisense primer, 5'-CACTCTCCAGAGCAGTAATT-3'; Sox8 sense primer, 5'-GACCAGTACTTGCCCCTCAAT-3' and Sox8 antisense primer,
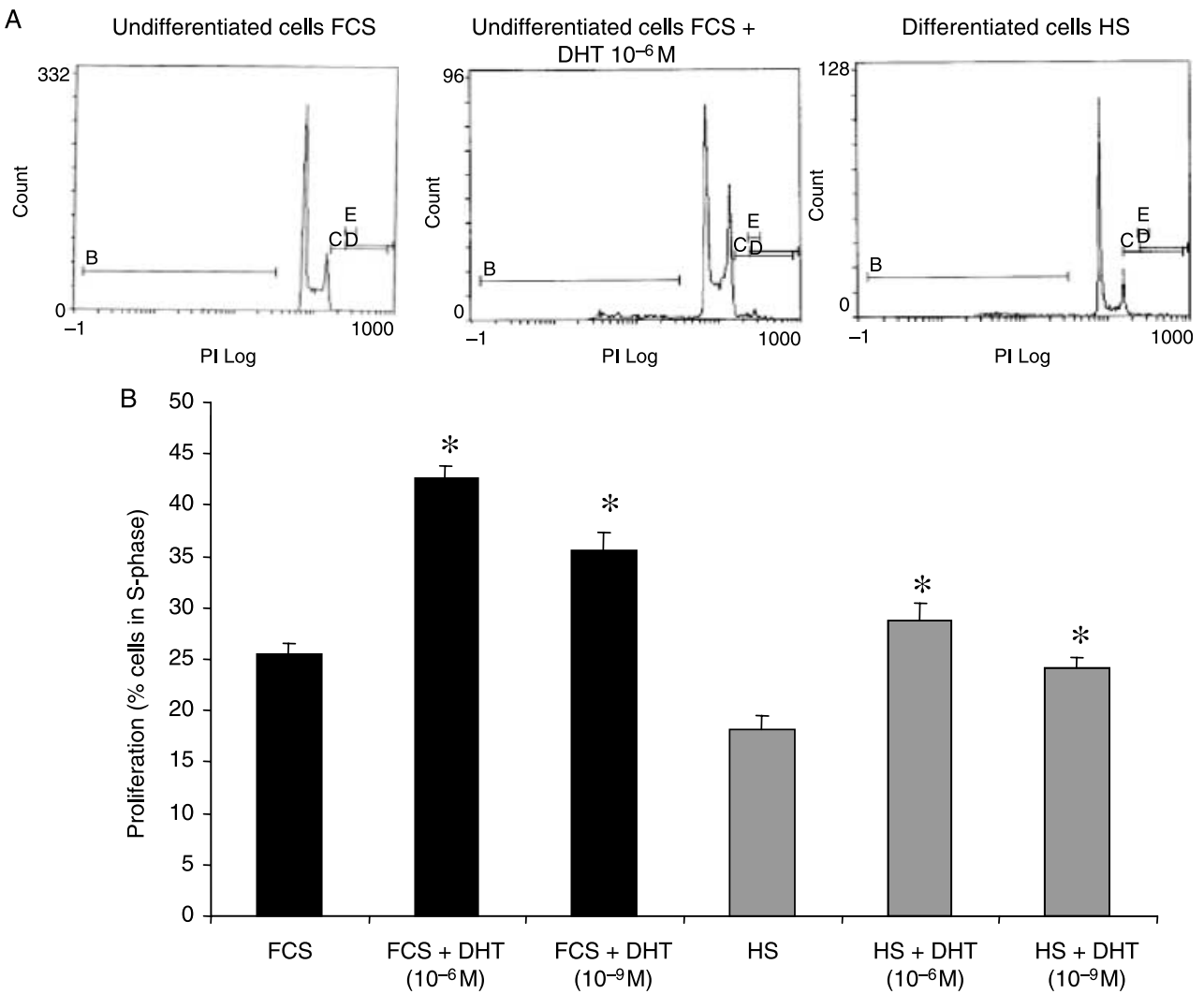

Figure 1 To analyze the effects of anabolic steroids on the molecular mechanisms of myoblast differentiation, mouse myoblast $\mathrm{C} 2 \mathrm{C} 12$ cells were treated dose-dependently with dihydrotestosterone (DHT). The effects on C2C12 proliferation were analyzed in normal medium (FCS) and in the presence of differentiation medium (HS) using cell cycle analysis. Treatment with DHT resulted in a stimulation of C2C12 proliferation. (A) Original cell diagram; (B) Quantitative determination of percentage of cells in 5 -phase. *Means are statistically different relative to the respective control group $(P<0 \cdot 05)$. 
5'-TCAGCTGCTCCGTCTTGATCT-3'; Notch sense primer, 5'-CCTTCTCACCAATACCTG-3' ${ }^{\prime}$ and Notch antisense primer, $5^{\prime}$-GATGCCCTCGGACCAATCA-3'; Delta sense primer, 5'-CTGAGGTGTAAGATGGAAGCG-3 $3^{\prime}$ and Delta antisense primer, $5^{\prime}$-CAACTGTCCATAGTCAATGG-3'; AR sense primer, 5'-GAGCAGATGGCAGTCATTCAG-3' and AR antisense primer,
5'-CAGCTCTCTTGCAATAGGCTG-3'; cyclophilin sense primer, $5^{\prime}$-GGATTCATGTGCCAGGGTGG-3 ${ }^{\prime}$ and cyclophilin antisense primer, $5^{\prime}$-CACATGCTTGCCATCCAGCC-3' ${ }^{\prime}$ cyclophilin was used as a reference gene. PCR products were sequenced to verify their identity and homology to the corresponding cDNA sequences in the EMBL databank.
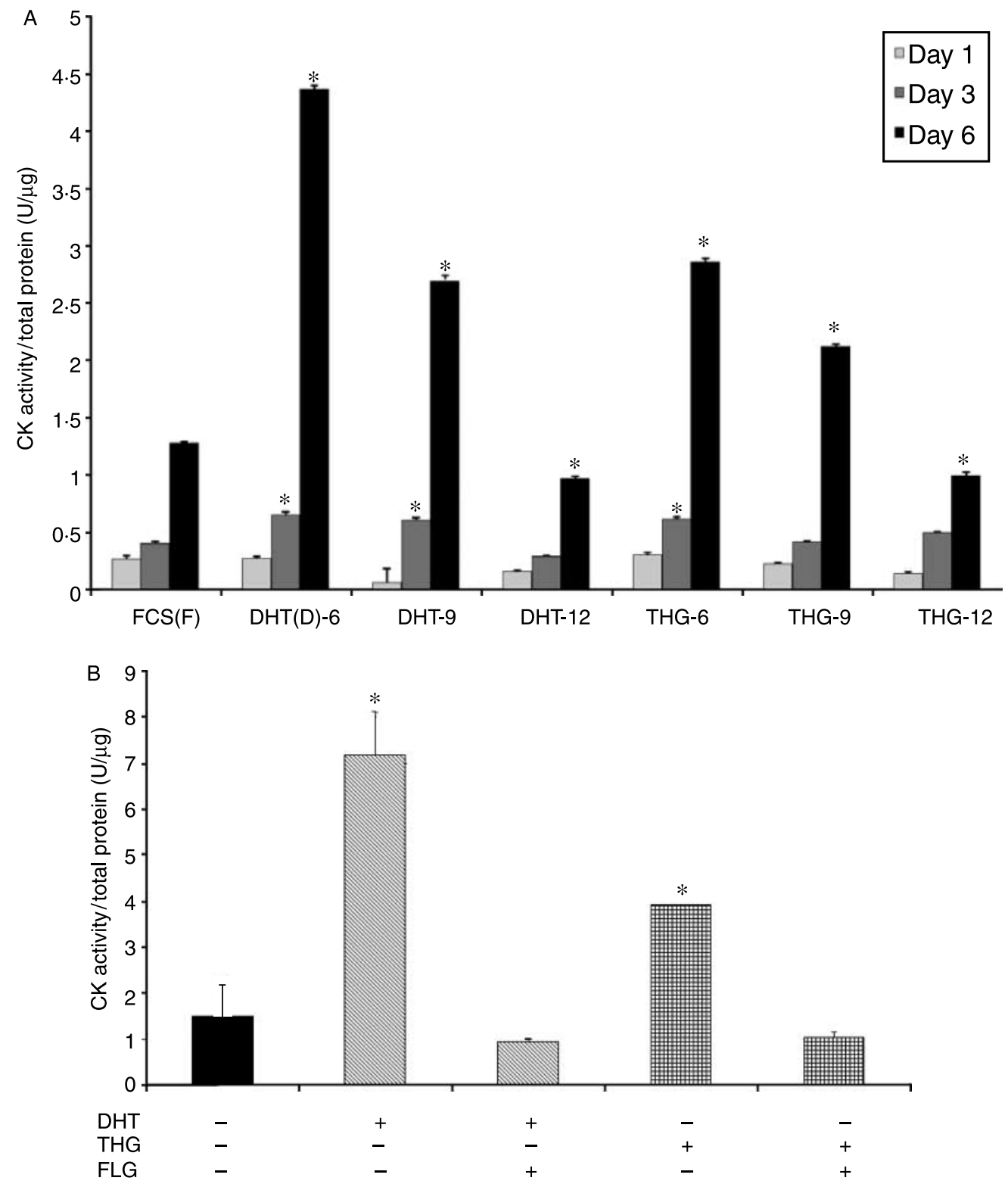

Figure 2 To analyze the effects of anabolic steroids on the molecular mechanisms of myoblast differentiation, mouse myoblast $\mathrm{C} 2 \mathrm{C} 12$ cells were treated dose-dependently with dihydrotestosterone (DHT) and tetrahydrogestrinone (THG). The effects on $\mathrm{C} 2 \mathrm{C} 12$ differentiation were analyzed by the measurement of creatine kinase (CK) activity. The treatment with dihydrotestosterone (DHT) and tetrahydrogesterone (THG) resulted in a stimulation of creatine kinase (CK) activity after 6 days, indicating the induction of differentiation towards myotubes $(\mathrm{A})$. This effect could be antagonized by the antiandrogen flutamide $(\mathrm{B})$. * Means are statistically different relative to the respective control group $(P<0 \cdot 05)$. 


\section{Statistical analysis}

The data are presented as mean \pm s.E.M. To determine statistical significance, a two-way Mann-Whitney $U$-test was applied. If not indicated otherwise the criterion for significance was set at $P \leq 0 \cdot 05$. All cell culture experiments were performed in triplicate.

\section{Results}

\section{Effects of androgens on $\mathrm{C2C} 12$ proliferation and differentiation}

To investigate the effects of androgens and anabolic steroids on the proliferation and differentiation of C2C12 cells, the cells were seeded in 24-well plates either in a regular or in a differentiation medium and treated with $10^{-6}$ or $10^{-9}$ M DHT. After 3 days, a cell cycle analysis was performed as described in Material and methods. At this point, the cells were grown to $\sim 50 \%$ confluence without cell-cell contact. Flow cytometry analysis revealed that proliferation was significantly induced by DHT treatment in FCS and in differentiation medium compared with untreated cells (Fig. 1). To investigate the effects of DHT on the induction of differentiation, the cells were seeded as described previously. The cells were treated with $10^{-6}$, $10^{-9}$, and $10^{-12} \mathrm{M}$ DHT or the anabolic steroid THG. After 1, 3, and 6 days, CK activity, a well-described marker of C2C12 cell differentiation (Lawson \& Purslow 2000), was measured in the cell lysates. As shown in Fig. 2A, after 6 days of treatment, a strong, dose-dependent induction of CK activity was visible in DHT- and THG-treated cells. The induction seems to be dose-dependent. To investigate whether the observed induction was $\mathrm{AR}$
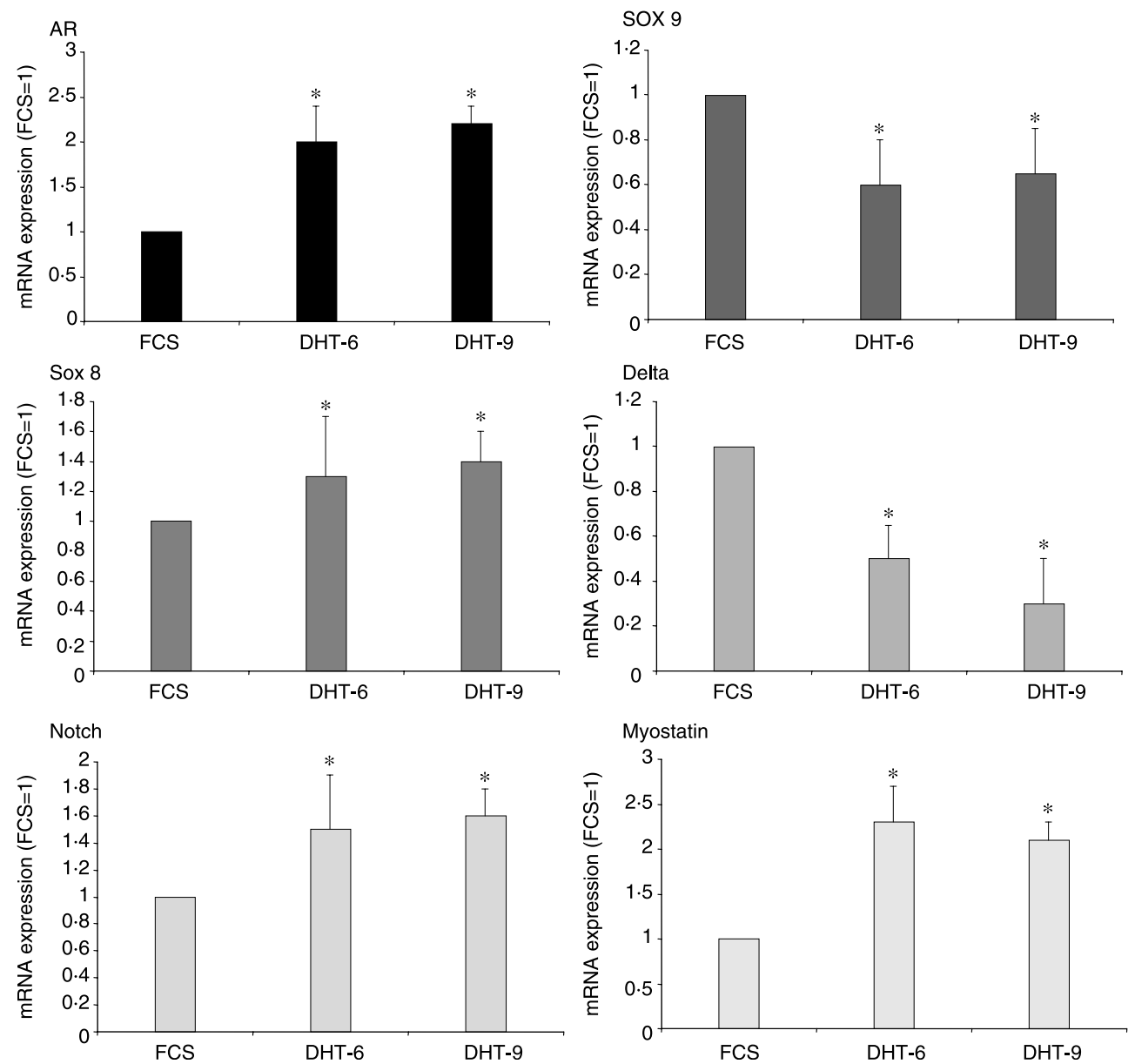

Figure 3 To investigate whether the observed effects of androgens on satellite cell differentiation and proliferation correlate with changes in gene expression, $\mathrm{C} 2 \mathrm{C} 12$ cells were seeded in 24-well plates and treated with $10^{-6}$ or $10^{-9} \mathrm{M}$ dihydrotestosterone (DHT). After 3 days, mRNA was isolated and the expression of the androgen receptor (AR) Notch, Delta, Sox8, Sox9, and myostatin was analyzed by quantitative real-time PCR. *Means are statistically different relative to the mRNA expression of the respective untreated control group (FCS) $(P<0.05)$. 
receptor-mediated, C2C12 cells were co-treated with DHT or THG and the antiandrogen flutamide (FLU). Figure 2B shows that the DHT- and THG-induced increase in CK activity could be antagonized by FLU.

\section{Effects of androgens on the expression of genes relevant for satellite cell differentiation}

To investigate whether the observed effects of androgens on satellite cell differentiation and proliferation correlate with the changes in the expression of genes relevant to satellite cell activity, C2C12 cells were seeded in 24-well plates and treated with $10^{-6}$ or $10^{-9} \mathrm{M}$ DHT. After 3 days, mRNA was isolated and the expression of Notch, Delta, Sox8, Sox9, and myostatin was analyzed in comparison with the mRNA expression of the AR. AR mRNA expression was detectable in C2C12 cells and was stimulated by DHT treatment (Fig. 3). Interestingly, the expression of all other genes analyzed was affected by DHT treatment. The expression of Notch, Sox8, and myostatin was stimulated; the expression of Delta and Sox9 was simultaneously repressed by DHT treatment.

\section{Effects of androgens on the expression of myostatin during myoblast differentiation}

Recently, we demonstrated that myostatin mRNA expression is regulated by androgens in rat skeletal muscle (Diel et al. 2007). To verify these in vivo results, the effects of androgens on myostatin expression during C2C12 cell differentiation were studied in the present study. The time-dependent analysis of myostatin protein and mRNA expression in the cell culture model demonstrated that myostatin expression followed a complex biphasic expression pattern during the process of differentiation (Fig. 4A and $\mathrm{B})$. Two days after seeding, myostatin protein and mRNA expression was very faint in the C2C12 cells. Myostatin expression strongly increased at day 4 . The expression levels declined at day 6 but a recovery of the expression was detectable in differentiated myotubes at day 8. The treatment of C2C12 with not only DHT but also THG resulted in a strong induction of myostatin mRNA expression on day 4 and on day 7 , compared with untreated cells (Fig. 5A). This effect could be antagonized by the antiandrogen flutamide (Fig. 5B).

\section{Effects of androgens on the expression of Pax7 during myoblast differentiation}

Pax7 is an important marker for satellite cells in the activated and proliferating states and plays an important role in the maintenance of the skeletal muscle satellite cell pool (Oustania et al. 2004). The role of
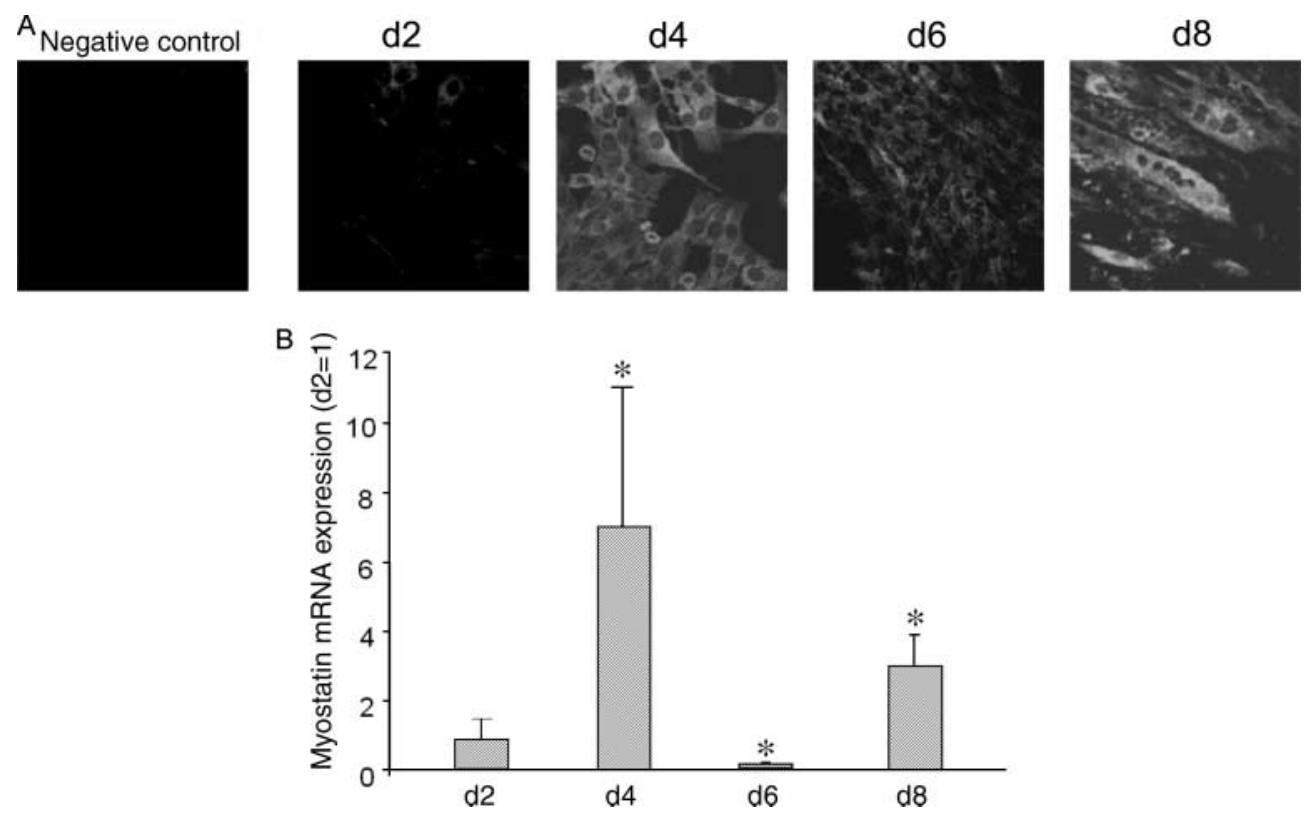

Figure 4 Analysis of myostatin expression during $\mathrm{C} 2 \mathrm{C} 12$ cell differentiation. The cells were seeded as described in Materials and methods. (A) After 2 (d2), 4 (d4), 6 (d6), and 8 days, the cells were fixed and stained with a myostatin-specific antibody. The analysis of expression was performed by confocal microscopy (magnification 200 X). (B) At the same time points, mRNA was isolated and myostatin mRNA expression was determined by quantitative real-time PCR as described in Materials and methods. *Means statistically different relative to the mRNA expression measured at day $2(P<0 \cdot 05)$. 

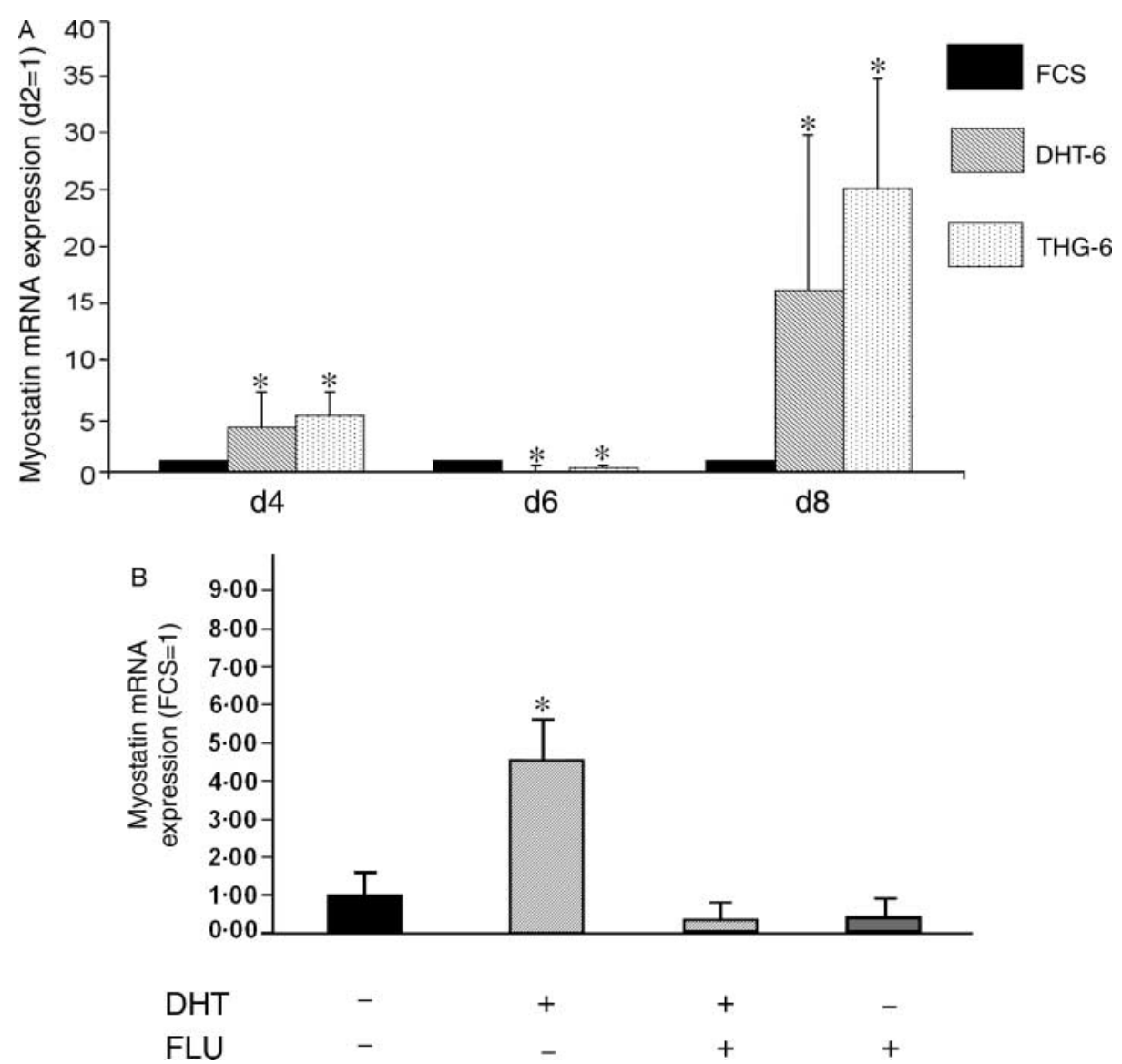

Figure 5 Effects of dihydrotestosterone (DHT) and THG on myostatin mRNA expression in C2C12 cells. The stimulation of myostatin mRNA expression by DHT was dose-dependent and could be antagonized by the antiandrogen flutamide. Myostatin mRNA expression was determined by quantitative real-time PCR as described in Materials and methods. *Means statistically different relative to the mRNA expression of the respective untreated control group (FCS) $(P<0.05)$. (A) Effects of DHT and THG. C2C12 cells were seeded in 24 -well plates and treated with $10^{-6} \mathrm{M} \mathrm{DHT}$ or THG. mRNA expression was measured after 4 (d4), 6 (d6) and 8 (d8) days. (B) To investigate whether modulation of myostatin expression by $\mathrm{DHT}$ is mediated via the androgen receptor, $\mathrm{C} 2 \mathrm{C} 12$ cells were seeded and treated with DHT, flutamide, and combinations of both. mRNA expression was measured after 4 days (d4).

Pax7 during the process of differentiation has been discussed in a controversial manner. Therefore, we have analyzed the effects of androgens on Pax7 expression during C2C12 cell differentiation. The time-dependent analysis of Pax7 protein expression demonstrated that the expression levels (percentage of positive nuclei) were low 2 days after seeding but increased strongly thereafter, reaching peak expression levels on day 6 . In differentiated myotubes, no Pax7 expression was detectable (Fig. 6A and B). The treatment with DHT resulted in a shift of the Pax7 expression pattern. In DHT-treated cells, a maximum of Pax7 expression levels were detectable after 4 days compared with 6 days in untreated cells (Fig. 7A and B).

\section{Discussion}

There is increasing evidence that endocrine factors, including steroids and growth factors, influence muscle growth and development throughout life. Therefore, the aim of this study was to investigate the effects of androgens and anabolic steroids during the process of differentiation of C2C12 cells toward myotubes. A special emphasis has been given to correlate the effects of androgens to the modulation of the expression of key genes involved in the process of satellite cell differentiation. An important observation in our study was that the treatment of $\mathrm{C} 2 \mathrm{C} 12$ cells with androgens and anabolic steroids not only stimulates 
A
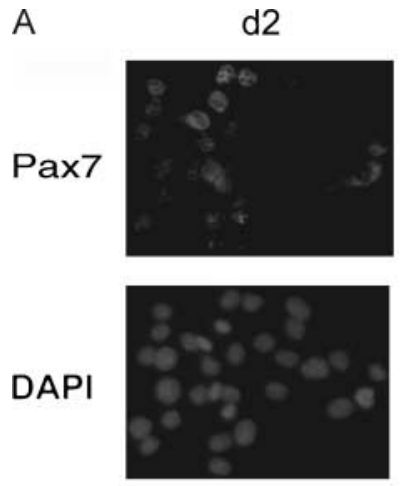

d4
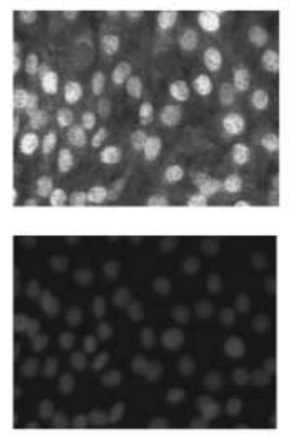

d6
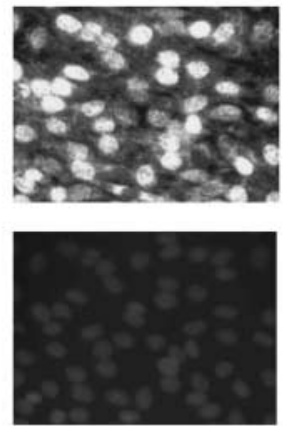

d8
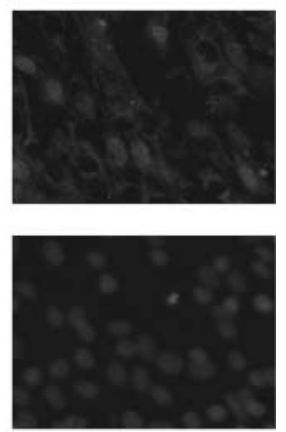

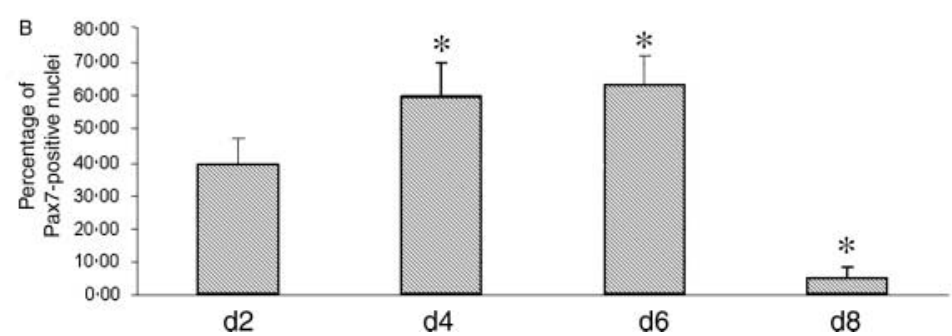

Figure 6 Analysis of Pax7 expression during C2C12 cell differentiation. (A) Time-dependent analysis of Pax7 protein expression. After 2 (d2), 4 (d4), 6 (d6), and 8 (d8) days cells were fixed and stained with a Pax7-specific antibody and DAPI. The analysis of expression was performed by confocal microscopy (magnification $200 \times$ ). (B) Calculation of the percentage of Pax7-positive nuclei. Indicated are the days of culture in FCS medium. *Means statistically different against day $2(P<0.05)$.

proliferation but also accelerates the process of differentiation toward myotubes. Figure 1 illustrates that treatment with androgens and anabolic steroids resulted in a dose-dependent increase in C2C12 cell proliferation. This observation is in agreement with the findings (Amthor et al. 2004) describing a stimulation of C2C12 cell proliferation by androgens and also demonstrates that anabolic steroids (in our case THG) induce similar effects. There are several reports in the literature describing the effects of androgens on myogenic differentiation. The results presented here confirm these findings. Our data clearly show that the process of differentiation is significantly accelerated by the presence of androgens. The evidence for this effect includes not only the time-dependent influence of androgens on the expression of CK (Fig. 2A), a welldescribed marker for differentiation toward myotubes (Lawson \& Purslow 2000) but also the observed shift in the expression pattern of Pax7 (Fig. 7). Mechanistically, we could demonstrate that the acceleration of differentiation by androgens is mediated via the AR. An inhibition of AR by co-treatment with the antiandrogen FLU completely antagonizes the stimulating effects not only of DHT but also of THG. In our opinion, androgens first stimulate proliferation that leads to an earlier cellular contact between the cells, which subsequently initiates the process of differentiation.
Figure 3 clearly shows that the effects of androgens are detectable at the molecular level in the C2C12 cells. The important observations are as follows: a) mRNA expression of the AR is detectable in C2C12 cells and b) AR expression is stimulated by DHT. The expression of $\mathrm{AR}$ in the C2C12 cells has also been reported in several other publications (Lee 2002, Chen et al. 2005). Although reports about the regulation of AR expression in C2C12 cells are rare, the finding that AR mRNA expression is stimulated by DHT treatment in C2C12 cells is in agreement with the observations made in other cell lines, such as LnCap and PC3 cells (Dai et al. 1996). Besides AR mRNA expression, we have analyzed the mRNA expression of known key regulators of satellite cell activity (Sox8, Sox9, Delta, Notch and myostatin). Interestingly, a modulation of mRNA expression by DHT could be observed for all genes evaluated. A very intriguing finding is our observation that Notch and Delta are regulated by DHT in an inverse manner. Whereas the expression of the Notch is stimulated, the Delta expression is simultaneously downregulated. Delta is a notch receptor ligand. Binding of Delta to Notch is described to induce differentiation (Conboy et al. 2005). An increase in the Notch expression can be taken as an indication of an increased tendency toward the induction of differentiation. In addition, our observation that the expression 
A
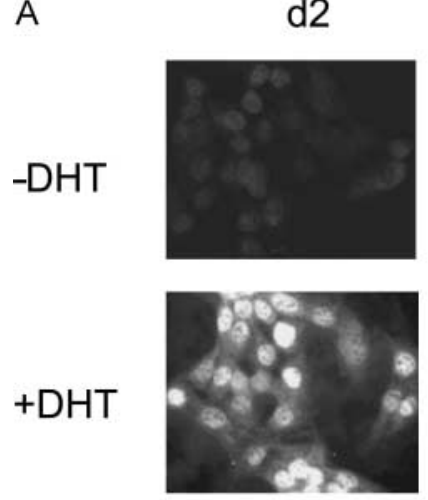

d4
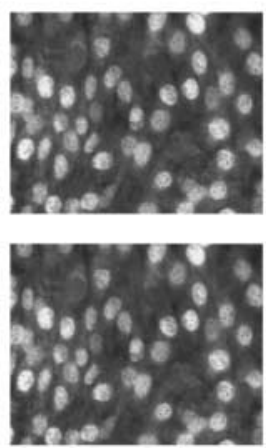

d6
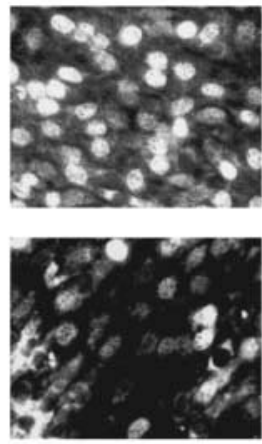

d8
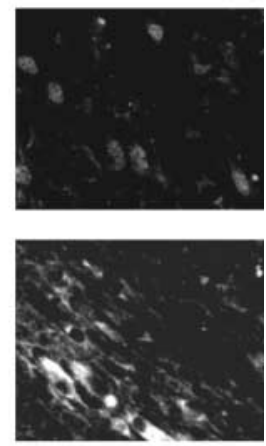

B

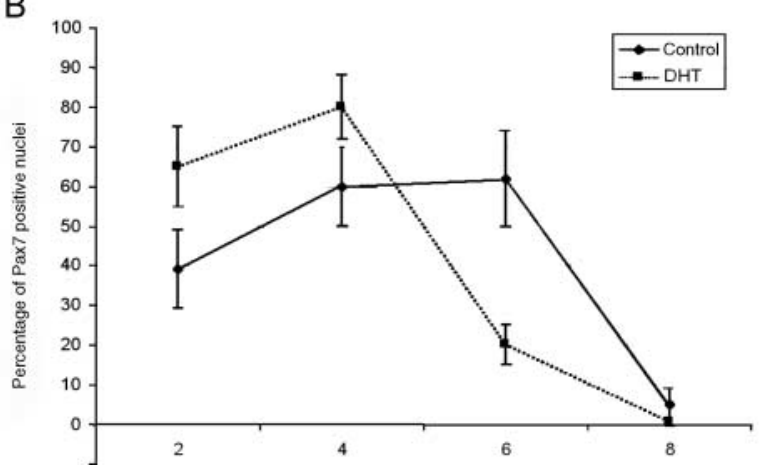

Figure 7 The effect of dihydrotestosterone (DHT) on Pax7 expression during $\mathrm{C} 2 \mathrm{C} 12$ cell differentiation. (A) Time-dependent analysis of Pax7 protein expression. After 2 (d2), 4 (d4), 6 (d6), and 8 (d8) days, the cells were fixed and stained with a Pax7-specific antibody and DAPI (not shown). (B) Calculation of the percentage of Pax7-positive nuclei.

of myostatin is modulated by androgens in C2C12 cells could be of great mechanistic significance. It has been described that myostatin is an important factor maintaining the satellite cells in a state of reversible quiescence (Amthor et al. 2006). Myostatin signaling involves interaction with MRFs, inhibiting the synthesis and activity of MyoD (Amthor et al. 2004, Guttridge 2004). At the cellular level, myostatin affects cell cycling by inhibiting the entry of satellite cells into S-phase (McCroskery et al. 2003, Amthor et al. 2004). As shown in Fig. 4, endogenous myostatin expression (mRNA and protein) is very low in C2C12 cells but rises significantly after the cellular contact increases (around day 4). During the process of differentiation, myostatin expression declined but strongly recovered in mature myotubes. A comparison of the expression pattern of myostatin with Pax7 indicates that the minimum of myostatin expression occurred when the Pax 7 expression reached its maximum. The observed expression pattern of Pax7 is in agreement with the published data. The activation of satellite cells is associated with a simultaneous stimulation of Pax7 and MyoD expression. The downregulation of Pax7 by constant MyoD expression is described to be the initial signal for differentiation of the cells (Halevy et al. 2004, Zammit et al. 2004). No Pax7 expression is detectable in differentiate myotubes (Seale et al. 2000, Dhawan \& Rando 2005, Zammit et al. 2006). A possible mechanistic interpretation of our observed expression patterns of myostatin and Pax7 could be that myostatin expression increases after cellular contact to stop the entry of cells into the S-phase of the cell cycle, thereby slowing down proliferation. The simultaneous increase in Pax7 expression inhibits the myostatin expression. Myostatin inhibition resulted in an increase in MyoD levels, which finally initiated differentiation. In differentiated myotubes, myostatin expression increased again and inhibited satellite cell differentiation via a paracrine mechanism. This hypothesis has to be investigated in further studies.

Our data shown in this paper demonstrate that androgens strongly affect these mechanisms. In Figs 3 and 5 , it is visible that myostatin mRNA expression is significantly increased by DHT and THG in undifferentiated and differentiated C2C12 cells. The identification of an androgen response element in the myostatin promotor supports a role of androgen in its 
regulation (Ma et al. 2001). Nevertheless, the effects of androgens on myostatin expression are discussed controversially. On the one hand, the observed stimulation of myostatin expression by DHT and THG is in agreement with recent findings from our laboratory demonstrating an increase in myostatin expression in the rat gastrocnemius muscle after treatment with testosterone and anabolic steroids (Diel et al. 2007). On the other hand, there are reports describing a downregulation of myostatin by androgens in the levator ani muscle (Mendler et al. 2007). The data provided in our paper demonstrate that myostatin expression is modulated by androgens in a very complex manner. As shown in Fig. 4, the myostain expression in differentiating C2C12 cells was not only stimulated but also downregulated depending on the treatment period. In addition, the type of the skeletal muscle may affect the androgen response. Recently, we could demonstrate that myostatin expression is downregulated after short-term endurance training in the gastrocnemius muscle, whereas its expression in the soleus muscle remained unaffected (Matsakas et al. 2005). However, the data shown in our paper clearly indicate that the observed effects of androgens on the expression of myostatin are modulated via the AR. As shown in Fig. 5b, co-treatment with the antiandrogen flutamide resulted in an antagonization of myostatin expression by DHT.

Summarizing the results of this study, our data provide evidence that key mechanisms of satellite cell differentiation are modulated by androgens. Androgens and anabolic steroids stimulate the proliferation of C2C12 cells, accelerate the process of differentiation toward myotubes, and stimulate the expression of myostatin in undifferentiated and differentiated cells. Our observation that androgens stimulate myostatin expression in C2C12 cells is supported by recent findings also demonstrating a stimulation of myostatin expression in vivo (Diel et al. 2007). Anabolic steroids and inhibition of myostatin expression have been shown to increase the muscle mass. However, our data presented in this study do not support the simple hypothesis that androgens may act via an inhibition of expression. More likely, androgens and myostatin cooperate in a complex fashion in the control of satellite cell activity. To complicate matters, the effects of physical activity have to be considered in this context. Recently, we could demonstrate that endurance training represses myostatin expression in vivo (Matsakas et al. 2005). More experiments are needed in the future to characterize these complex interactions both in vivo and in vitro. Nevertheless, these findings offer important clues to understand the mechanisms underlying the cellular and molecular effects of anabolic steroids and may have implications with respect to the treatment of muscular diseases and the improvement of doping analytical methods.

\section{Acknowledgements}

We thank Peter Muhn, Schering AG Berlin for his support. We also thank J Seibel and T Hertrampf for their assistance in performing the animal experiments and for editing the manuscript. This study was supported by a grant from the World Anti Doping Agency (WADA). We declare that there is no conflict of interest to the research reported that would prejudice its impartiality.

\section{References}

Amthor H, Nicholas G, McKinnell I, Kemp CF, Sharma M, Kambadur R \& Patel K 2004 Follistatin complexes myostatin and antagonises myostatin-mediated inhibition of myogenesis. Developmental Biology 270 19-30.

Amthor H, Otto A, Macharia R, McKinnell I \& Patel K 2006 Myostatin imposes reversible quiescence on embryonic muscle precursors. Developmental Dynamics 235 672-680.

Artaza JN, Bhasin S, Magee TR, Reisz-Porszasz S, Shen R, Groome NP, Meerasahib MF \& Gonzalez-Cadavid NF 2005 Myostatin inhibits myogenesis and promotes adipogenesis in $\mathrm{C} 3 \mathrm{H} 10 \mathrm{~T}(1 / 2)$ mesenchymal multipotent cells. Endocrinology 146 3547-3557.

Benjamin CL, Jenster G \& Piedrahita JA 2004 Use of artificial androgen receptor coactivators to alter myoblast proliferation. Journal of Steroid Biochemistry and Molecular Biology 91 111-119.

Blau HM, Pavlath GK, Hardeman EC, Chiu CP, Silberstein L, Webster SG, Miller SC \& Webster C 1985 Plasticity of the differentiated state. Science $230758-766$.

Chen Y, Zajac JD \& MacLean HE 2005 Androgen regulation of satellite cell function. Journal of Endocrinology 186 21-31.

Conboy IM, Conboy MJ, Wagers AJ, Girma ER, Weissman IL \& Rando TA 2005 Rejuvenation of aged progenitor cells by exposure to a young systemic environment. Nature 433 760-764.

Dai JL, Maiorino CA, Gkonos PJ \& Burnstein KL 1996 Androgenic up-regulation of androgen receptor cDNA expression in androgenindependent prostate cancer cells. Steroids 61 531-539.

Dhawan J \& Rando TA 2005 Stem cells in postnatal myogenesis: molecular mechanisms of satellite cell quiescence, activation and replenishment. Trends in Cell Biology 15 666-673.

Diel P, Olff S, Schmidt S \& Michna H 2002 Effects of the environmental estrogens bisphenol A, o,p'-DDT, p-tert-octylphenol and coumestrol on apoptosis induction, cell proliferation and the expression of estrogen sensitive molecular parameters in the human breast cancer cell line MCF-7. Journal of Steroid Biochemistry and Molecular Biology 80 61-70.

Diel P, Friedel A, Geyer H, Kamber M, Laudenbach-Leschowsky U, Schänzer W, Thevis M, Vollmer G \& Zierau O 2007 Characterisation of the pharmacological profile of desoxymethyltestosterone (Madol), a steroid misused for doping. Toxicology Letters 169 64-71.

Grobet L, Martin LJ, Poncelet D, Pirottin D, Brouwers B, Riquet J, Schoeberlein A, Dunner S, Ménissier F, Massabanda J et al. 1997 A deletion in the bovine myostatin gene causes the double-muscled phenotype in cattle. Nature Genetics 17 71-74.

Guttridge DC 2004 Signaling pathways weigh in on decisions to make or break skeletal muscle. Current Opinion in Clinical Nutrition and Metabolic Care 7 443-450.

Halevy O, Piestun Y, Allouh MZ, Rosser BW, Rinkevich Y, Reshef R, Rozenboim I, Wleklinski-Lee M \& Yablonka-Reuveni Z 2004 Pattern of Pax7 expression during myogenesis in the posthatch chicken establishes a model for satellite cell differentiation and renewal. Developmental Dynamics 231 489-502. 
Lawson MA \& Purslow PP 2000 Differentiation of myoblasts in serumfree media: effects of modified media are cell line-specific. Cells, Tissues, Organs 167 130-137.

Lee DK 2002 Androgen receptor enhances myogenin expression and accelerates differentiation. Biochemical and Biophysical Research Communications 294 408-413.

Ma K, Mallidis C, Artaza J, Taylor W, Gonzalez-Cadavid N \& Bhasin S 2001 Characterization of $5^{\prime}$-regulatory region of human myostatin gene: regulation by dexamethasone in vitro. American Journal of Physiology. Endocrinology and Metabolism 281 E1128-E1136.

Matsakas A, Friedel A, Hertrampf T \& Diel P 2005 Short-term endurance training results in a muscle-specific decrease of myostatin mRNA content in the rat. Acta Physiologica Scandinavica 183 299-307.

Mauro A 1961 Satellite cell of skeletal muscle fibers. Journal of Biophysical and Biochemical Cytology 9 493-495.

McCroskery S, Thomas M, Maxwell L, Sharma M \& Kambadur R 2003 Myostatin negatively regulates satellite cell activation and selfrenewal. Journal of Cell Biology 162 1135-1147.

McPherron AC, Lawler AM \& Lee SJ 1997 Regulation of skeletal muscle mass in mice by a new TGF- $\beta$ superfamily member. Nature 387 83-90.

Mendler L, Baka Z, Kovács-Simon A \& Dux L 2007 Androgens negatively regulate myostatin expression in an androgen-dependent skeletal muscle. Biochemical and Biophysical Research Communications 361 237-242.

Oustania S, Hause G \& Braun T 2004 Pax7 directs postnatal renewal and propagation of myogenic satellite cells but not their specification. EMBO Journal 23 3430-3439.

Schuelke M, Wagner KR, Stolz LE, Hübner C, Riebel T, Kömen W, Braun T, Tobin JF \& Lee SJ 2004 Myostatin mutation associated with gross muscle hypertrophy in a child. New England Journal of Medicine 350 2682-2688.

Scimè A \& Rudnicki MA 2004 Anabolic potential and regulation of the skeletal muscle satellite cell populations. Journal of Cell Biology 166 347-357.
Seale P, Sabourin LA, Girgis-Gabardo A, Mansouri A, Gruss P \& Rudnicki MA 2000 Pax7 is required for the specification of myogenic satellite cells. Cell 102 777-786.

Sinha-Hikim I, Taylor WE, Gonzalez-Cadavid NF, Zheng W \& Bhasin S 2004 Androgen receptor in human skeletal muscle and cultured muscle satellite cells: up-regulation by androgen treatment. Journal of Clinical Endocrinology and Metabolism 89 5245-5255.

Veldhuis JD, Roemmich JN, Richmond EJ, Rogol AD, Lovejoy JC, Sheffield-Moore M, Mauras N \& Bowers CY 2005 Endocrine control of body composition in infancy, childhood, and puberty. Endocrine Reviews 26 114-146.

Wagner KR, Liu X, Chang X \& Allen RE 2005 Muscle regeneration in the prolonged absence of myostatin. PNAS 102 2519-2524.

Wozniak AC \& Anderson JE 2005 Single-fiber isolation and maintenance of satellite cell quiescence. Biochemistry and Cell Biology 83 674-676.

Wozniak AC, Kong J, Bock E, Pilipowicz O \& Anderson JE 2005 Signaling satellite-cell activation in skeletal muscle: markers, models, stretch, and potential alternate pathways. Muscle and Nerve 31 283-300.

Zammit PS, Golding JP, Nagata Y, Hudon V, Partridge TA \& Beauchamp JR 2004 Muscle satellite cells adopt divergent fates: a mechanism for self-renewal? Journal of Cell Biology 166 347-357.

Zammit PS, Relaix F, Nagata Y, Ruiz AP, Collins CA, Partridge TA \& Beauchamp JR 2006 Pax7 and myogenic progression in skeletal muscle satellite cells. Journal of Cell Science 119 1824-1832.

Received in final form 12 February 2008

Accepted 27 February 2008

Made available online as an Accepted Preprint

27 February 2008 